Keywords: anastrozole; endocrine treatment; fulvestrant; hormone-receptor-positive cancer; large operable or locally advanced breast cancer; neo-adjuvant

\title{
Clinical and genomic analysis of a randomised phase II study evaluating anastrozole and fulvestrant in postmenopausal patients treated for large operable or locally advanced hormone-receptor-positive breast
}

\section{cancer}

Nathalie Quenel-Tueux ${ }^{*}$, , Marc Debled ${ }^{1}$, Justine Rudewicz 1,2,3,4,5, Gaetan MacGrogan 1,2,3, Marina Pulido 6,7, Louis Mauriac ${ }^{1}$, Florence Dalenc ${ }^{8}$, Thomas Bachelot ${ }^{9}$, Barbara Lortal ${ }^{1}$, Christelle Breton-Callu ${ }^{1}$, Nicolas Madranges ${ }^{1}$, Christine Tunon de Lara ${ }^{1}$, Marion Fournier ${ }^{1}$, Hervé Bonnefoi ${ }^{1,2,3}$, Hayssam Soueidan ${ }^{4}$, Macha Nikolski ${ }^{3,4,5}$, Audrey Gros ${ }^{1,2,3}$, Catherine Daly ${ }^{10}$, Henry Wood ${ }^{10}$, Pamela Rabbitts ${ }^{10}$ and Richard lggo*,1,2,3

\begin{abstract}
${ }^{1}$ Institut Bergonié Comprehensive Cancer Centre, 229 Cours de l'Argonne, F-33000 Bordeaux, France; ${ }^{2}$ INSERM U916, 229 Cours de I'Argonne, F-33000 Bordeaux, France; ${ }^{3}$ University Bordeaux, 16 Avenue Léon Duguit, F-33608 Pessac, France; ${ }^{4}$ Bordeaux Bioinformatics Centre, University Bordeaux, 146, rue Léo Saignat, F-33076 Bordeaux, France; ${ }^{5}$ CNRS UMR5800, Bordeaux Computer Science Lab, 351 Cours de la Libération, F-33405 Talence, France; 'Inserm Clinical Investigation Centre CIC1401, Epidemiological Unit, 229 Cours de l'Argonne, Bordeaux 33076, France; ${ }^{7}$ Clinical and Epidemiological Research Unit, Institut Bergonie, 229 Cours de l'Argonne, Bordeaux 33076, France; ${ }^{8}$ Institut Claudius Regaud, IUCT-Oncopole Toulouse, 1 Avenue Irène Joliot-Curie, F-31059 Toulouse, France; ${ }^{9}$ CLCC Lyon, 28 Promenade Léa et Napoléon Bullukian, F-69008 Lyon, France and ${ }^{10}$ Leeds Institute of Cancer and Pathology, University of Leeds, Beckett Street, Leeds LS9 7TF, UK
\end{abstract}

Background: The aim of this study was to assess the efficacy of neoadjuvant anastrozole and fulvestrant treatment of large operable or locally advanced hormone-receptor-positive breast cancer not eligible for initial breast-conserving surgery, and to identify genomic changes occurring after treatment.

Methods: One hundred and twenty post-menopausal patients were randomised to receive $1 \mathrm{mg}$ anastrozole (61 patients) or $500 \mathrm{mg}$ fulvestrant (59 patients) for 6 months. Genomic DNA copy number profiles were generated for a subgroup of 20 patients before and after treatment.

Results: A total of 108 patients were evaluable for efficacy and 118 for toxicity. The objective response rate determined by clinical palpation was $58.9 \%(95 \% \mathrm{Cl}=45.0-71.9)$ in the anastrozole arm and $53.8 \%(95 \% \mathrm{Cl}=39.5-67.8)$ in the fulvestrant arm. The breast-conserving surgery rate was $58.9 \%(95 \% \mathrm{Cl}=45.0-71.9)$ in the anastrozole arm and $50.0 \%(95 \% \mathrm{Cl}=35.8-64.2)$ in

*Correspondence: Dr N Quenel-Tueux; E-mail: n.quenel-tueux@bordeaux.unicancer.fr or Professor R Iggo; E-mail: r.iggo@bordeaux.unicancer.fr Past presentations: European Breast Cancer Conference (EBCC-9), Glasgow, Scotland, 19-21 March 2014 (Presentation). San Antonio Breast Cancer Symposium, 9-13 December 2014, San Antonio, Texas (Poster presentation).

Received 23 June 2015; revised 5 June 2015; accepted 15 June 2015; published online 14 July 2015

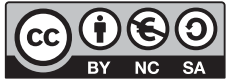

BPEN 0 
the fulvestrant arm. Pathological responses $>50 \%$ occurred in 24 patients (42.9\%) in the anastrozole arm and $13(25.0 \%)$ in the fulvestrant arm. The Ki-67 score fell after treatment but there was no significant difference between the reduction in the two arms (anastrozole 16.7\% (95\% $\mathrm{Cl}=13.3-21.0)$ before, 3.2\% (95\% $\mathrm{Cl}=1.9-5.5)$ after, $n=43$; fulvestrant $17.1 \%(95 \% \mathrm{Cl}=13.1-22.5)$ before, $3.2 \%(95 \% \mathrm{Cl}=1.8-5.7)$ after, $n=38)$ or between the reduction in $\mathrm{Ki}-67$ in clinical responders and non-responders. Genomic analysis appeared to show a reduction of clonal diversity following treatment with selection of some clones with simpler copy number profiles.

Conclusions: Both anastrozole and fulvestrant were effective and well-tolerated, enabling breast-conserving surgery in over 50\% of patients. Clonal changes consistent with clonal selection by the treatment were seen in a subgroup of patients.

Endocrine therapy is widely used to treat hormone-receptorpositive breast cancer. Neoadjuvant endocrine therapy, where drug treatment is given before surgery, is commonly given to elderly patients with large operable or locally advanced hormone-receptorpositive breast cancer because it has a favourable toxicity profile and permits breast-conserving surgery in $40-50 \%$ of patients who would otherwise have required mastectomy (Semiglazov et al, 2007; Mathew et al, 2009; Chia et al, 2010; Debled et al, 2014). In this setting, treatment with aromatase inhibitors is considered as a standard in post-menopausal patients (Eiermann et al, 2001; Smith et al, 2005). Fulvestrant is an oestrogen receptor downregulator with a different mechanism of action. Several trials have assessed fulvestrant in women with metastatic breast cancer (Chia et al, 2010; Robertson et al, 2012; Robertson et al, 2014), but in the neoadjuvant setting, there are only a few small studies comparing $500 \mathrm{mg}$ fulvestrant to an aromatase inhibitor (Massarweh et al, 2011).

Resistance to hormonal therapy can arise through multiple mechanisms (reviewed by Ali and Coombes, 2002). Mutation of the oestrogen receptor can confer estradiol-independent activation of transcription (Weis et al, 1996) and has been identified in metastatic breast cancers treated with hormonal therapy (reviewed by Segal and Dowsett, 2014). Activation of growth factor signalling pathways, leading to phosphorylation of ER $\alpha$ on serines 118 and 167 in the ligand-independent transactivation domain, activates $\mathrm{ER} \alpha$ in the absence of estradiol (reviewed by Ali and Coombes, 2002). Increased expression of coactivators, in particular amplification of the NCOA3 and CCND1 genes, and decreased expression of corepressors, are additional mechanisms of resistance to hormonal therapy (reviewed by Ali and Coombes, 2002). Finally, conversion to a progenitor or stem-like state in which ESR1 is not required for growth, for example, through expression of ELF5 (Kalyuga et al, 2012) or SOX2 (Piva et al, 2014), confers oestrogen independence. Given the wide range of mechanisms, it is possible that resistance to fulvestrant and aromatase inhibitors could arise through different mechanisms. An important difference between the drugs is that aromatase inhibitors deprive the cell of oestrogen but do not induce degradation of the receptor, whereas fulvestrant induces $\mathrm{ER} \alpha$ degradation. An increase in ER $\alpha$ level, for example, by amplification of the gene, might offset a reduced availability of ligand, leading to resistance to aromatase inhibitors. Resistance to fulvestrant seems unlikely to arise through this mechanism. Instead, mutations interfering with $\mathrm{ER} \alpha$ degradation or activating the pathway downstream of the receptor might be favoured with fulvestrant. Endocrine therapy typically causes tumours to regress over a period of several months, during which time clonal selection may gradually occur. Unlike chemotherapy, hormonal therapy is not clastogenic or mutagenic, so genetic changes arising during treatment are unlikely to be secondary events provoked by iatrogenic DNA damage. Hence, hormonal therapy given in a neoadjuvant trial provides an ideal opportunity to study resistance to endocrine therapy arising in vivo.

Given the lack of clinical data on fulvestrant in patients with large operable or locally advanced hormone-receptor-positive breast cancer, and the potential to identify differences in the mechanism of resistance using the neoadjuvant model, we decided to perform a multicentre randomised phase II clinical trial of anastrozole and fulvestrant. This manuscript reports both the clinical findings of this trial and the genomic changes arising during endocrine therapy in the subgroup of patients for whom the tumour cell content was at least $50 \%$ in the samples taken before and after treatment.

\section{METHODS}

Protocol approval. The study was approved by the South-West France and Overseas Departments, Committee for Protection of Research Subjects (Comité de Protection des Personnes, Sud-Ouest et Outre-Mer III, 2007/57) and conducted according to the Declaration of Helsinki, EU clinical trials directives (2001/20/CE) and Good Clinical Practice guidelines. The clinicaltrials.gov registry number is NCT0087858. Patients gave signed informed consent to participate in the study and to allow the use of their tumour samples for research including genomic analysis. Samples from the trial were stored in the Bergonie Institute Tumour Bank in compliance with French laws on tumour banks (authorisation no. AC-2008-812). The translational study was approved by the French authorities (authorisation no. M70674-4201). The funders had no role in the study design, data analysis or manuscript drafting.

Study design. This was a non-comparative multicentre randomised phase II study in which patients from three French centres were randomly assigned in a 1:1 ratio to receive either $1 \mathrm{mg}$ per day anastrozole administered orally for 6 months (control arm) or $500 \mathrm{mg}$ of fulvestrant administered as an intramuscular infusion every 4 weeks for 6 months with a loading dose in the first month (experimental arm). Anastrozole (ARIMIDEX, Astra Zeneca, London, UK) was provided as $1 \mathrm{mg}$ film-coated tablets. Fulvestrant (FASLODEX, Astra Zeneca) was provided as a $250 \mathrm{mg} / 5 \mathrm{ml}$ solution. Before starting treatment, three trucut biopsies were taken for research purposes; two were frozen and one was fixed in Molecular Fixative (Hostein et al, 2011). Follow-up was carried out at 2, 4 and 6 months to assess the clinical response and tolerance. Drug treatment was continued until the day before surgery. Surgery at 6 months was proposed to all patients. The decision for breast-conserving surgery or total mastectomy at the end of neoadjuvant endocrine treatment was assessed by a multidisciplinary board comprising a medical oncologist, a surgeon and a radiation oncologist. After 6 months of treatment, residual tumour was resected surgically, and frozen and formalin-fixed samples were again taken for research purposes. Adjuvant treatments were decided according to each centre's policy.

Eligibility. Patients were eligible if they met the following criteria: post-menopausal woman; histologically confirmed non-metastatic T2-T3-T4 invasive breast cancer; grade I or II; oestrogen and/or progesterone-receptor-positive; clinically measurable disease at 
baseline; not eligible for breast-conserving surgery at baseline; HER2 positive or negative. Women with grade III tumours were eligible only if they were aged 65 years or over. Patients with inflammatory breast cancer, N2 disease, a history of cancer within the past 5 years, or a contra-indication to hormonal therapy were not eligible.

End points. The primary end point was the objective response rate (ORR) at 6 months determined by clinical palpation, defined as the rate of complete and partial responses (CR $+\mathrm{PR})$ according to RECIST Criteria (Version 1.0). The same doctor was responsible for clinical assessment initially and at 6 months. Secondary end points included: ORR determined by ultrasound and mammography at 6 months based on RECIST Criteria; rate of breastconserving surgery at 6 months; pathological response using the Sataloff classification (Sataloff et al, 1995); and safety profile examination using common terminology criteria for adverse events (CTCAE, version 3.0, DCTD, NCI, NIH; http://ctep.cancer.gov). Exploratory analyses were carried out for the preoperative endocrine prognostic index (PEPI score; Ellis et al, 2008) and changes in the fraction of tumour nuclei expressing Ki-67. Followup was planned for 5 years.

Statistical considerations. The sample size for this non-comparative phase II trial was based on the primary end point, ORR. According to the Fleming one-step method, for a null hypothesis of $40 \%$ ORR and an alternative hypothesis of $60 \%$ ORR, 52 assessable patients needed to be treated in each treatment arm (104 in total), with a one-sided alpha of $5 \%$ and a power of $90 \%$. The experimental arm was deemed interesting for further research if at least 27 clinical responses out of 52 treated eligible patients were observed. This decision rule corresponded to rejecting the null hypothesis. After adjusting the sample size by $15 \%$ to allow for non-evaluable patients, 120 patients were required. The randomisation was stratified by centre. Two analysis populations were considered: (i) the safety population, defined as all patients who received at least one dose of the allocated study medication (a dose of anastrozole or an injection of fulvestrant), and (ii) the efficacy population (primary endpoint), defined as all eligible (no major eligibility deviations) and evaluable patients who started the allocated treatment and who were evaluated at 6 months. Patients discontinuing treatment due to progression or death from any cause were considered as treatment failures. Patients who missed the evaluation at 6 months due to treatment discontinuation for toxicity, refusal to participate or lost to follow-up were excluded from the efficacy population.

Pathological assessment. Ki-67 was scored centrally by a pathologist (GMG) in a blinded manner according to the recommendations of Dowsett et al (2011) by counting at least 1000 tumour nuclei per sample after staining with mib1 antibody. Ki-67 was scored before treatment on the core biopsy and after treatment on the surgical resection specimen. Tumours were defined as hormone-receptor positive or negative by local pathologists with a $10 \%$ cutoff for scoring as positive. To evaluate the pathological response, the Sataloff classification was used (Sataloff et al, 1995). The PEPI score was calculated as described by Ellis et al (2008).

Genomic study. Only samples with at least 50\% tumour cells after treatment were selected for the genomic substudy (the tumour cell content was frequently below this cutoff after treatment). DNA was purified from frozen samples and analysed on a GAIIx DNA sequencer (Illumina, San Diego, CA, USA). Low-depth wholegenome sequencing data were converted to DNA copy number plots with the CNAnorm package (Gusnanto et al, 2012) in $\mathrm{R}$ statistical software (R Core Team, 2013) as described by (Wood et al, 2010). Base quality, mapping quality, read depth and tumour cell content are summarised in Supplementary Table 6, and further details of the bioinformatics approaches are given in the Supplementary Methods file.

\section{RESULTS}

Baseline characteristics. A total of 120 patients were enrolled in three French comprehensive cancer centres between March 2008 and May 2012 and randomly assigned to anastrozole (61 patients, 51\%) or fulvestrant (59 patients, 49\%) arm. Two patients withdrew their consent. Ten patients were not assessable for the efficacy analysis: four in the standard arm and six in the experimental arm (see Figure 1 for details). A total of 118 patients and 108 patients were assessable for the safety and efficacy analyses, respectively (Figure 1). Patient and tumour characteristics are summarised in Table 1. Baseline characteristics were balanced between the two treatment arms, but there were more T2 N0 Grade 1 tumours in the anastrozole arm and more lobular carcinomas in the fulvestrant arm.

Clinical response and surgery. Of the 56 patients eligible and evaluable for efficacy in the anastrozole arm, 7 achieved a CR and 26 a PR, giving an ORR of $58.9 \%$ (95\% CI $=45.0-71.9)$. Of the 52 patients eligible and evaluable for efficacy in the fulvestrant arm, 6 achieved a CR and 22 achieved a PR, giving an ORR of $53.8 \%$ (95\% CI = 39.5-67.8; Table 2). Analysis including all eligible patients gave very similar results (Supplementary Table 1). Eight tumours progressed under therapy: six in the fulvestrant arm and two in the anastrozole arm. Five patients were HER2-positive at inclusion, of whom one progressed and four had stable disease. In the anastrozole arm, 33 patients underwent breast-conserving surgery (58.9\%, 95\% CI $=45.0-71.9)$. In the fulvestrant arm, 26 patients underwent breast-conserving surgery $(50.0 \%, 95 \% \mathrm{CI}=35.8-64.2)$.

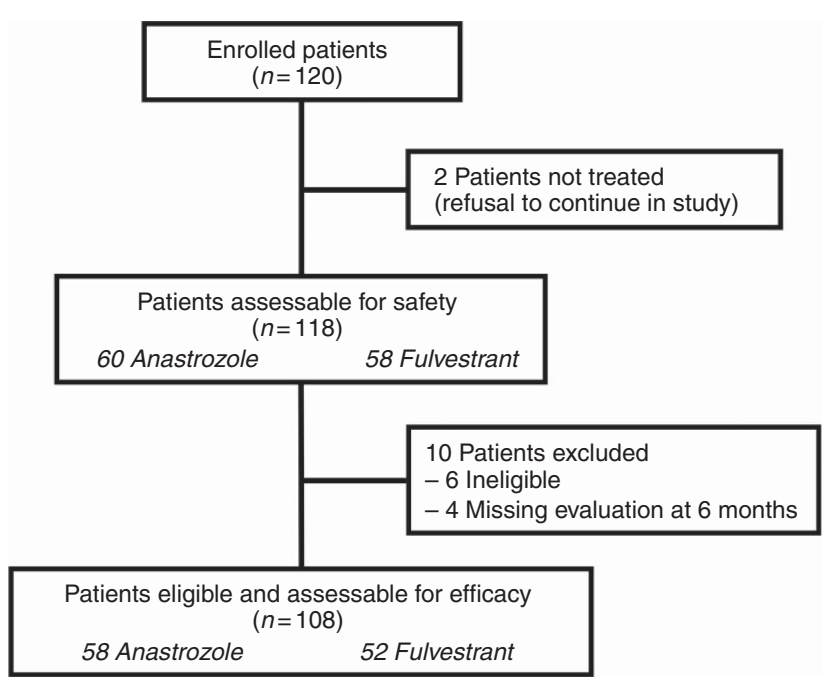

Figure 1. Flow chart of patient enrolment and analysis populations. Two patients withdrew their consent and did not start the allocated treatment; a total of 118 patients (60 anastrozole and 58 fulvestrant) were thus assessable for safety. Six patients did not meet the eligibility criteria: four had grade 3 tumours and were younger than 65 years, one had an N2 nodal status, and one had bone metastases. A further four patients were not assessable for the primary end point: one patient refused both evaluation at 6 months and surgery; two patients stopped treatment before the 6 months due to toxicity (one elderly patient had asthenia and vertigo after 4 months of fulvestrant treatment with stable disease and was offered treatment with anastrozole, and one patient had musculoskeletal pain after 2 months of anastrozole); and the fourth patient was lost to follow-up. A total of 108 patients were thus assessable and eligible for the primary efficacy end point. 
Table 1. Patient and tumour characteristics

\begin{tabular}{|c|c|c|}
\hline & Anastrozole arm & Fulvestrant arm \\
\hline & $N=61(\%)$ & $N=59(\%)$ \\
\hline \multicolumn{3}{|l|}{ Age (years) } \\
\hline Median (range) & $69(54-86)$ & $71(51-91)$ \\
\hline \multicolumn{3}{|l|}{ ECOG PS } \\
\hline 0 & $53(86.9)$ & $49(83.1)$ \\
\hline 1 & $8(13.1)$ & $10(16.9)$ \\
\hline \multicolumn{3}{|l|}{ Tumour size (mm) } \\
\hline Median (range) & $45(25-90)$ & $50(30-110)$ \\
\hline \multicolumn{3}{|l|}{ T classification } \\
\hline $\mathrm{T} 2$ & $43(70.5)$ & $32(54.2)$ \\
\hline T3 & $9(14.8)$ & $13(22.0)$ \\
\hline T4 & $2(3.3)$ & $8(13.6)$ \\
\hline T4a & $0(0)$ & $1(1.7)$ \\
\hline T4b & $6(9.8)$ & $4(6.8)$ \\
\hline $\mathrm{T} 4 \mathrm{c}$ & $1(1.6)$ & $1(1.7)$ \\
\hline \multicolumn{3}{|l|}{$\mathrm{N}$ classification } \\
\hline NO & $39(63.9)$ & $29(49.2)$ \\
\hline N1 & $22(36.1)$ & $29(49.2)$ \\
\hline NX & $0(0)$ & $1(1.6)$ \\
\hline \multicolumn{3}{|l|}{ Histology } \\
\hline Ductal invasive carcinoma & $45(73.8)$ & $39(66.1)$ \\
\hline Lobular invasive carcinoma & $14(23.0)$ & $19(32.2)$ \\
\hline Mucinous adenocarcinoma & $2(3.3)$ & $1(1.7)$ \\
\hline \multicolumn{3}{|l|}{ Histologic grades } \\
\hline I & $11(18.0)$ & $8(13.6)$ \\
\hline ॥ & 45 (73.8) & $44(74.6)$ \\
\hline III & $3(4.9)$ & $5(8.5)$ \\
\hline Not available & $2(3.3)$ & $2(3.4)$ \\
\hline \multicolumn{3}{|l|}{ Receptor status } \\
\hline ER+ & $61(100)$ & $59(100)$ \\
\hline $\mathrm{PR}+$ & $54(88.5)$ & 55 (93.2) \\
\hline PR - & $6(9.8)$ & $3(5.1)$ \\
\hline PR not available & $1(1.6)$ & $1(1.7)$ \\
\hline \multicolumn{3}{|l|}{ HER2 $^{a}$} \\
\hline Positive & $4(6.6)$ & $3(5.1)$ \\
\hline Negative & $55(90.2)$ & 55 (93.2) \\
\hline Missing & $2(3.3)$ & $1(1.7)$ \\
\hline \multicolumn{3}{|c|}{$\begin{array}{l}\text { Abbreviations: } E C O G \quad P S=\text { performance status; } E R=\text { oestrogen receptor; } P R= \\
\text { progesterone receptor. } \\
\mathrm{a}_{\text {HER2 positive if immunohistochemistry } 3+\text { or if FISH amplified. }}\end{array}$} \\
\hline
\end{tabular}

Two patients in the anastrozole arm and six in the fulvestrant arm did not undergo surgery (see the Supplementary Material for details); both patients in the anastrozole arm and three in the fulvestrant arm had a biopsy at 6 months.

Pathological response, ER, PR, Ki67 and PEPI score. Pathological response data at 6 months for the primary tumour were available for 92 patients (Table 2). Pathological reports were not evaluable for eight patients. No complete pathological responses were observed (Sataloff 'Tumour A'; Sataloff et al, 1995). Pathological responses greater than 50\% (Sataloff 'Tumour B') were observed in $43 \%$ of patients in the anastrozole arm and in $25 \%$ of patients in the fulvestrant arm. Nodal status NO (Sataloff NA or NB) was observed in $34 \%$ of patients in the anastrozole arm and $27 \%$ of patients in the fulvestrant arm.

ER scores at baseline and after 6 months of neoadjuvant therapy were available for 96 patients. The percentage of ER-positive tumour nuclei in each arm before and after treatment is shown in Figure 2A and B, with summary statistics in Supplementary Table 2 and Allred scores in Supplementary Table 3. The figure shows that there was a large decrease in ER staining in the fulvestrant arm (Wilcoxon test, $\left.P<10^{-4}\right)$ but no change in the anastrozole arm $(P=0.8)$. There was
Table 2. Clinical and pathological response at 6 months

\begin{tabular}{|c|c|c|}
\hline & $\begin{array}{c}\text { Anastrozole } \\
\text { arm }\end{array}$ & $\begin{array}{c}\text { Fulvestrant } \\
\text { arm }\end{array}$ \\
\hline Clinical response & $N=56$ & $N=52$ \\
\hline $\begin{array}{l}\text { CR } \\
\text { PR } \\
\text { SD } \\
\text { PD } \\
\text { ORR (CR + PR) }\end{array}$ & $\begin{aligned} 7 & (12.5) \\
26 & (46.4) \\
21 & (37.5) \\
2 & (3.6) \\
33 & (58.9)\end{aligned}$ & $\begin{array}{r}6(11.5) \\
22(42.3) \\
18(34.6) \\
6(11.5) \\
28(53.8)\end{array}$ \\
\hline Surgery & $N=56$ & $N=52$ \\
\hline $\begin{array}{l}\text { Breast-conserving surgery } \\
\text { Mastectomy } \\
\text { No surgery }\end{array}$ & $\begin{aligned} 33 & (58.9) \\
21 & (37.5) \\
2 & (3.6)\end{aligned}$ & $\begin{array}{l}26(50) \\
20(38.5) \\
6(11.5)\end{array}$ \\
\hline \multicolumn{3}{|l|}{ Pathological response } \\
\hline $\begin{array}{l}\text { Sataloff classification } T \\
\text { TB (Pathological response } \geqslant 50 \%) \\
\text { TC } \\
\text { TD } \\
\text { Missing }\end{array}$ & $\begin{aligned} N & =56 \\
24 & (42.9) \\
23 & (41.1) \\
3 & (5.4) \\
6 & (10.7)\end{aligned}$ & $\begin{array}{c}N=52 \\
13(25.0) \\
24(46.2) \\
5(9.6) \\
10(19.3)\end{array}$ \\
\hline $\begin{array}{l}\text { Sataloff classification } \mathrm{N} \\
\text { NA } \\
\text { NB } \\
\text { NC } \\
\text { ND } \\
\text { Missing }\end{array}$ & $\begin{aligned} N & =56 \\
3 & (5.4) \\
16 & (28.6) \\
20 & (35.7) \\
7 & (12.5) \\
10 & (17.9)\end{aligned}$ & $\begin{array}{l}N=52 \\
6(11.5) \\
8(15.4) \\
12(23.1) \\
15(28.8) \\
11(21.2)\end{array}$ \\
\hline $\begin{array}{l}\text { PEPI score } \\
\begin{array}{l}0 \\
1-3 \\
>3\end{array}\end{array}$ & $\begin{array}{c}N=41 \\
8(19.5) \\
17(41.5) \\
16(39.0)\end{array}$ & $\begin{array}{c}N=35 \\
4(11.4) \\
19(54.3) \\
12(34.3)\end{array}$ \\
\hline \multicolumn{3}{|c|}{$\begin{array}{l}\text { Abbreviations: } \mathrm{CR}=\text { complete response; } \mathrm{NA}=\text { evidence of therapeutic effect, no residual } \\
\text { disease; } \mathrm{NB}=\mathrm{no} \text { evidence of therapeutic effect, no axillary metastasis; } \mathrm{NC}=\text { evidence of } \\
\text { therapeutic effect, axillary metastasis present; } \mathrm{ND}=\text { no evidence of therapeutic effect, } \\
\text { axillary metastasis present; } \mathrm{ORR}=\text { objective response rate; } \mathrm{PD}=\text { progressive disease; } \\
\mathrm{PEPI}=\text { preoperative endocrine prognostic index; } \mathrm{PR}=\text { partial response, } \mathrm{SD}=\text { stable disease; } \\
\mathrm{TA}=\text { complete or nearly complete response; } \mathrm{TB}=\text { therapeutic response over } 50 \% ; \mathrm{TC}= \\
\text { therapeutic response under } 50 \% ; \mathrm{TD}=\text { no evidence of therapeutic effect. }\end{array}$} \\
\hline
\end{tabular}

no correlation between ER and clinical response (Figure 2A and B, and Supplementary Figure 1).

PR scores at baseline and after 6 months of neoadjuvant therapy were available for 95 patients. The percentage of PR-positive tumour nuclei in each arm before and after treatment is shown in Figure 2C and D, with summary statistics in Supplementary Table 2 and Allred scores in Supplementary Table 3. The figure shows that there was a large decrease in PR staining in both arms (fulvestrant arm, $P<10^{-6}$; anastrozole arm, $P<10^{-6}$ ). There was no correlation between PR and clinical response (Figure $2 \mathrm{C}$ and $\mathrm{D}$, and Supplementary Figure 1).

Ki-67 scores at baseline and after 6 months of neoadjuvant therapy were available for 81 patients. The percentage of Ki-67positive tumour nuclei in each arm before and after treatment is shown in Figure 2E and F. The Ki-67 score fell substantially after treatment in both arms (Table 3). There was a weak correlation between the reduction in PR and the reduction in Ki-67 in the clinical responders in the anastrozole arm (Spearman $r=0.46$ ); no other correlations were observed between Ki-67 and receptor expression (Supplementary Figure 1). There was no significant difference between the reduction in Ki-67 in the two arms, or between the reduction in Ki-67 in clinical responders and nonresponders (Figure $2 \mathrm{E}$ and F, Supplementary Figure 1; Wilcoxon test not significant).

The PEPI score (PEPI for relapse-free survival, Ellis et al, 2008) after 6 months of therapy was calculated for 76 patients. The proportion of patients in each of the three PEPI risk subgroups was broadly similar in both treatment arms (Table 2).

Toxicity. Both treatments were well tolerated. Grade I/II adverse events occurring in $\geqslant 5 \%$ of patients are presented in Supplementary 

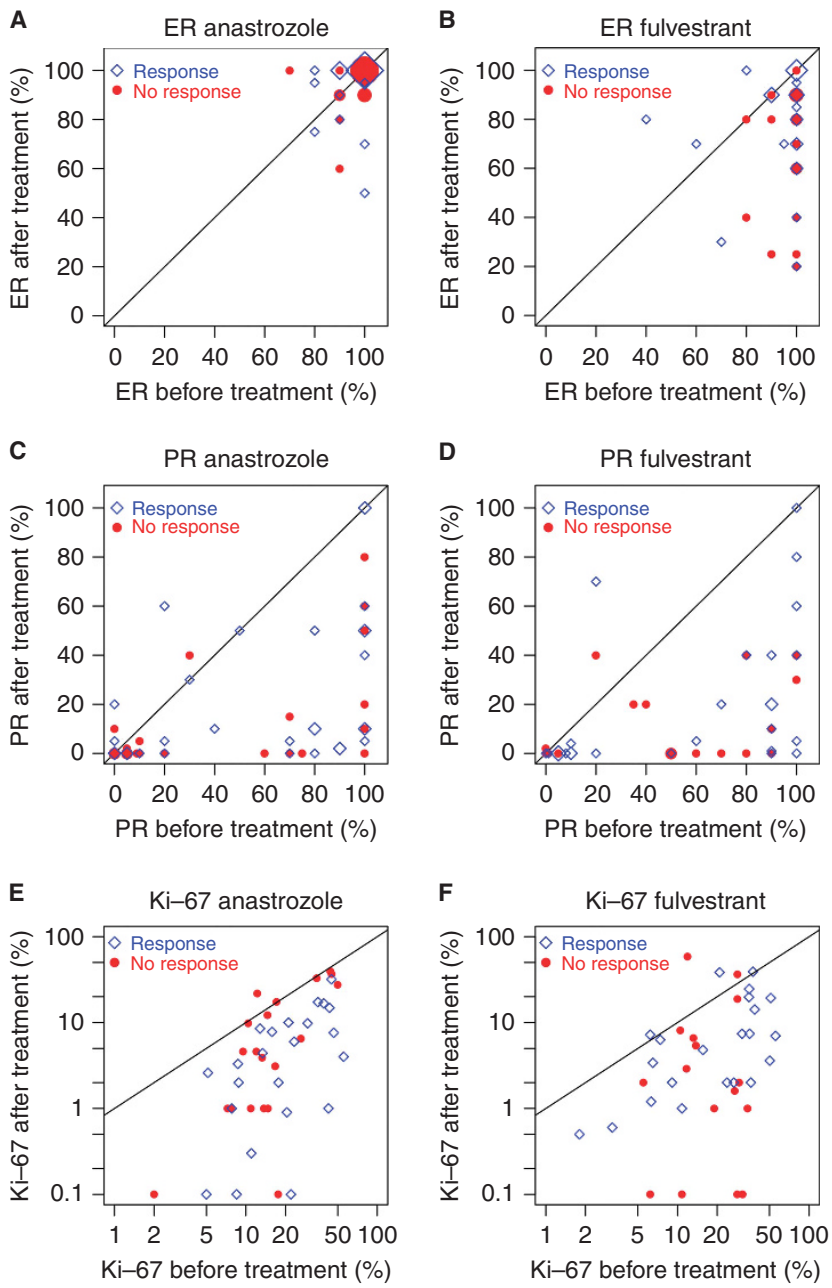

Figure 2. Plots showing $\mathrm{ER}, \mathrm{PR}, \mathrm{Ki}-67$ and response. (A and $\mathbf{B}$ ) Oestrogen receptor; ( $\mathbf{C}$ and $\mathbf{D})$ progesterone receptor; ( $\mathbf{E}$ and $\mathbf{F}) \mathrm{Ki}-67$; ( $A, C$ and $\mathbf{E}$ ) anastrozole arm; (B, D and F) fulvestrant arm. When points fall below the diagonal line $(y=x)$ in each plot, the measured variable declined after treatment. At least 1000 tumour cells per tumour were counted to estimate the percentage with Ki-67-positive nuclei. The axes are plotted on a log scale for $\mathrm{Ki}-67$ because Ki-67 has a log-normal distribution. The area of the plotting symbols is proportional to the number of cases at a given point (e.g., many samples in the anastrozole arm had 100\% ER-positive nuclei before and after treatment, so the plotting symbols are larger for these values).

Table 4. The most common grade 1-2 treatment-related toxicities were hot flushes $(22 \%$ in the anastrozole arm and $17 \%$ in the fulvestrant arm) and musculoskeletal pain, which was more frequent in the anastrozole arm (40\%) than in the fulvestrant arm $(21 \%)$. Fatigue was more common in the fulvestrant arm $(29 \%$ vs $10 \%)$ and reaction at the injection site was only reported in the fulvestrant arm (16\%; Supplementary Table 4). Grade 3 musculoskeletal pain was reported in one patient in the anastrozole arm and grade 3 hot flushes in three patients in the fulvestrant arm. Four serious adverse events occurred but none were treatment related: endometrial atrophy, bronchitis and a kidney cancer were reported in the fulvestrant arm and an ankle fracture after a fall was reported in the anastrozole arm.

Genomic DNA copy number profiling. The translational study was performed on samples from 20 patients (labelled H01-H20). The main criterion for including patients in the translational study was the availability of material, in particular, the presence of at
Table 3. Ki-67 before and after treatment

\begin{tabular}{|c|c|c|}
\hline & $\begin{array}{c}\text { Before } \\
\text { treatment (\%) }\end{array}$ & $\begin{array}{c}\text { After } \\
\text { treatment (\%) }\end{array}$ \\
\hline \multicolumn{3}{|c|}{ Both arms $(n=81)$} \\
\hline $\begin{array}{l}\text { Mean } \\
95 \% \mathrm{Cl}\end{array}$ & $\begin{array}{c}16.9 \\
14.3-20.1\end{array}$ & $\begin{array}{c}3.2 \\
2.2-4.7\end{array}$ \\
\hline \multicolumn{3}{|c|}{ Anastrozole arm $(n=43)$} \\
\hline $\begin{array}{l}\text { Mean } \\
95 \% \mathrm{Cl}\end{array}$ & $\begin{array}{c}16.7 \\
13.3-21.0\end{array}$ & $\begin{array}{c}3.2 \\
1.9-5.5\end{array}$ \\
\hline \multicolumn{3}{|c|}{ Fulvestrant arm $(n=38)$} \\
\hline $\begin{array}{l}\text { Mean } \\
95 \% \mathrm{Cl}\end{array}$ & $\begin{array}{c}17.1 \\
13.1-22.5 \\
\end{array}$ & $\begin{array}{c}3.2 \\
1.8-5.7 \\
\end{array}$ \\
\hline
\end{tabular}

least $50 \%$ tumour cells in the post-treatment sample. In five cases, two independent biopsies were tested before treatment and in four cases two different parts of the surgical specimen were tested after treatment. In the remaining cases, single samples were tested before and after treatment. Next-generation sequencing was performed at low depth and reads were counted in moving windows to estimate DNA copy number. Hierarchical clustering was used to detect broad patterns in the data (Figure 3; the Treeview data files are provided as Supplementary Data to permit examination of the heatmap at high resolution). As expected for $\mathrm{ER}+$ breast cancer, many tumours had minimally rearranged 'simplex' copy number profiles with gains of 1q/16p and loss of 16q. Apart from H06 and H13, all samples from the same tumour clustered together. Overall, the clustering shows that the differences between tumours were in general much greater than the differences before and after treatment of the same tumour.

Focal differences in tumour profiles before and after treatment. Eight tumours contained classic amplicons previously reported in $\mathrm{ER}+$ breast tumours (Supplementary Figure 2). Most amplicons were present before and after treatment but three tumours (H09, H14 and H15) showed focal changes in the copy number profile after treatment. Figure 4B shows the copy number profiles for tumour H09. Potential driver genes in six amplicons are highlighted with arrows. The ratio of copy number before and after treatment for these genes is shown in Figure 4A (the blue dots are for H09, the other tumours are given black dots). The ratios in Figure $4 \mathrm{~A}$ confirm the impression from the profiles in Figure $4 \mathrm{~B}$ that new amplicons containing ESR1, ATG5 and MSH2 appeared after treatment. FISH was used to confirm the presence of the ESR1 amplicon. The gene was highly amplified after treatment (Figure 4D, green dots), but, unexpectedly, it was also amplified before treatment (Figure $4 \mathrm{C}$ ). The green dots are more diffuse before treatment because an organic fixative was used instead of formaldehyde, which precludes precise quantification of the difference. There was no increase in ER staining by IHC after treatment in H09, perhaps because the signal was already so strong (Supplementary Table 5). Progesterone receptor was undetectable by IHC in $\mathrm{H} 09$ both before and after treatment (Supplementary Table 5), as commonly occurs in luminal B tumours. Tumour H14 showed focal changes after treatment, including a copy number increase after treatment on $c h r 14 \mathrm{q}$ in a region containing the FOXA1 gene (Supplementary Figure 3). Both H09 and H14 were in the anastrozole arm. In summary, copy number profiles showed the presence of focal differences in three tumours after treatment, including two showing changes affecting genes implicated in oestrogenic signalling (ESR1 and FOXA1).

Large-scale differences in tumour profiles before and after treatment. We corrected for differences in normal tissue 


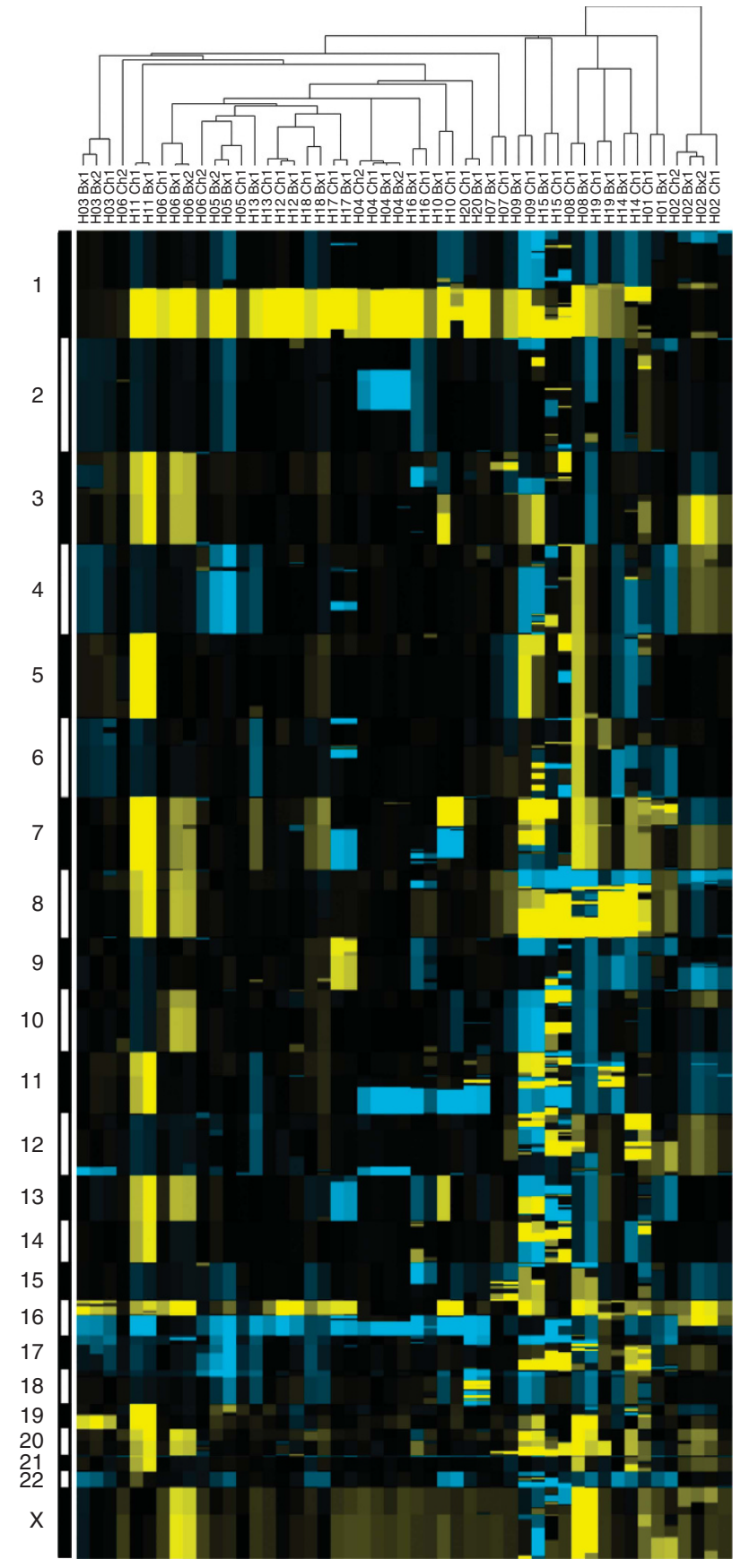

Figure 3. Heatmap showing hierarchical clustering of the 20 samples $(\mathrm{H} 01-\mathrm{H} 20)$ before $(\mathrm{Bx})$ and after $(\mathrm{Ch})$ treatment. All tumours except H06Ch2 have abnormalities of chr1 and/or chr16. Colours: yellow, increase in copy number; blue: decrease in copy number. One node has been flipped to highlight the differences between $\mathrm{H} 13$ before and after treatment.

contamination then calculated a $Z$ score for the presence of large-scale differences between samples, as described in the Supplementary Methods file and Supplementary Figure 4. Seven pairs of tumours stood out as being significantly different (H08, H09, H10, H13, H14, H15 and H19; Supplementary Table 6). Intriguingly, the commonest change after treatment was not the appearance of new changes but the disappearance of old ones. Specifically, in four tumours the profile became simpler through the disappearance of gains and losses of whole chromosomes or chromosome arms. We can exclude dilution of the signal by normal tissue because the 1q gain was still clearly visible in all the affected tumours. Figure 5A shows tumour $\mathrm{H} 13$ in which a gain of chr7 and losses of chr4, 6, 11, 12, 17 and 18 disappeared, leaving only the changes on chrl and 16. Figure 5B shows tumour H08 in which changes on chr2, 7 and 15 became more normal; the overall profile shows many other rearrangements that persisted. Figure $5 \mathrm{C}$ shows tumour $\mathrm{H} 10$ in which changes on chr3, 13 and 18 disappeared, loss of chr10 and 15 appeared, whereas changes on chr1, 7, 11, 16 and 22 remained. Figure 5D shows tumour H19 in which changes on chr3 and 10 disappeared, 20q was gained and changes on many other chromosomes remained. The differences after treatment of tumour H06 did not reach significance in our $Z$ test (Supplementary Table 6), probably because of the low tumour cell content after treatment, but if chrl is used as the reference chromosome in the linear model, chr3, 7, 8, 10, 13 and 18 appear to have reverted to a more normal profile (Supplementary Figure 2). Three of the tumours that became simpler showed stable disease and two a PR; three were in the fulvestrant arm and two were in the anastrozole arm (Supplementary Table 6). In summary, genomic profiles showed differences after treatment in one-third of cases, and the commonest change was a simplification of the profiles.

\section{DISCUSSION}

The main conclusion from this study is that anastrozole and fulvestrant are effective neoadjuvant treatments for post-menopausal patients with large operable or locally advanced ER + breast cancers. Both drugs made breast-conserving surgery a viable option for some women who were not eligible for it initially. The main conclusion from the genomic study is that breast tumours undergoing neoadjuvant endocrine therapy show clonal variation that could be explained by clonal selection.

The primary clinical end point, the ORR, was $58.9 \%$ in the anastrozole arm and $53.8 \%$ in the fulvestrant arm. These figures are consistent with rates around $50 \%$ observed in previous studies (Eiermann et al, 2001; Mathew et al, 2009; Ellis et al, 2011). The percentage of women receiving breast-conserving surgery $(58.9 \%$ for anastrozole and $50 \%$ for fulvestrant) was also similar to that previously reported after letrozole, anastrozole or tamoxifen (40 and 50\%, Eiermann et al, 2001; Smith et al, 2005). In conclusion, our results are at least as good as those with 3-4 months of aromatase inhibitors and therefore are consistent with longer therapy (e.g., 6 months) being better than shorter.

We chose to compare anastrozole with fulvestrant because the literature does not provide clear guidance on their use in the neoadjuvant setting (Howell et al, 2004; Smith et al, 2005; Massarweh et al, 2011; Kuter et al, 2012; Ciruelos et al, 2014). Comparative studies have demonstrated that both treatments are effective in the metastatic setting (Mauriac et al, 2003; Robertson et al, 2012). Aside from the question of efficacy, parenteral administration of fulvestrant has potential clinical advantages in patients with swallowing problems or neurological problems, such as Alzheimer's disease. Our decision to treat for 6 months was based on our previous study in elderly or frail women (Mauriac et al, 2002). It is longer than was initially recommended, but other groups have now reported favourable outcomes after neoadjuvant endocrine treatment for up to 7.5 months (Dixon et al, 2009; Carpenter et al, 2014).

The trend towards prolonging adjuvant hormonal therapy out to 10 years means there is considerable interest in using neoadjuvant therapy to provide early evidence of drug efficacy. Reassessment of drug efficacy after 6 months of neoadjuvant hormonal therapy provides reassurance that a therapeutic opportunity is not being lost and could potentially save many 
A
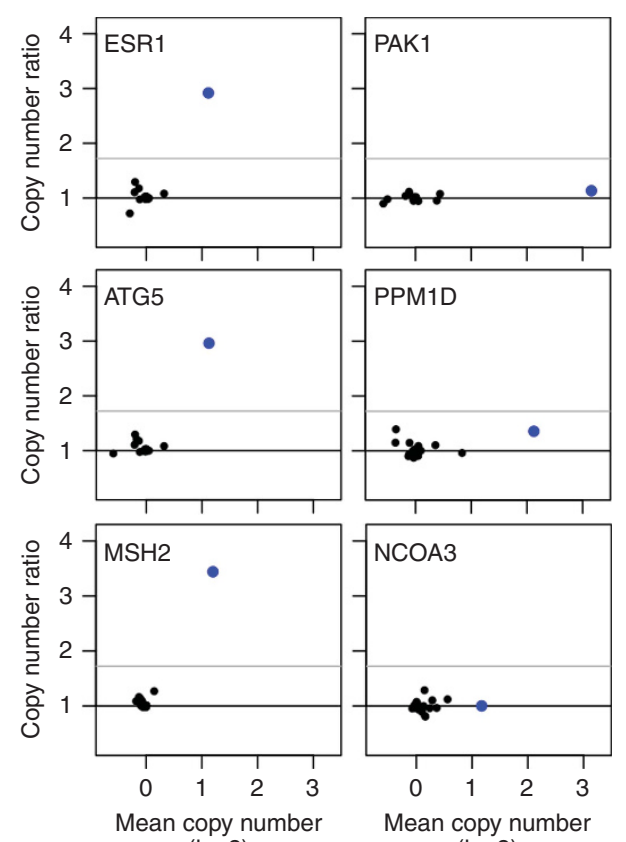

$(\log 2)$
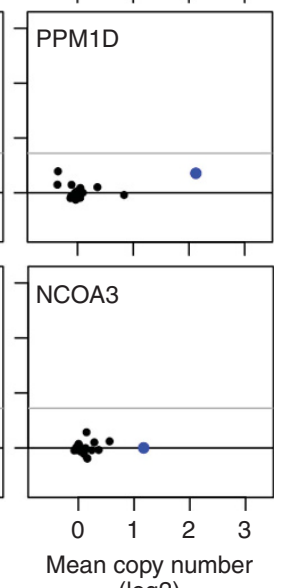

$(\log 2)$
B
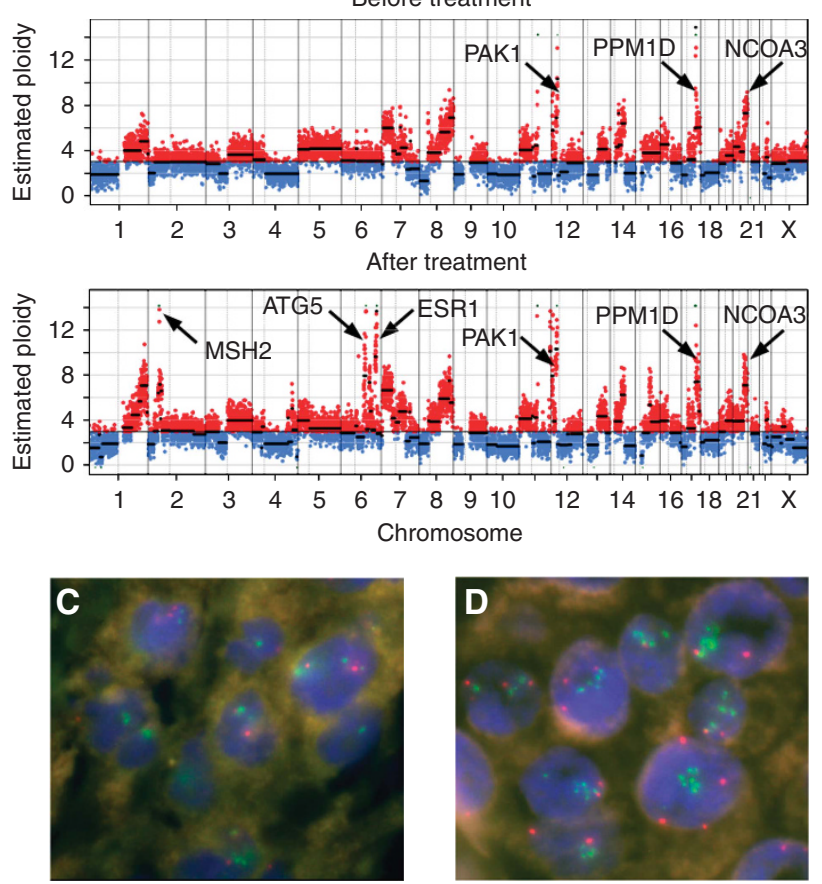

Figure 4. Genomic analysis before and after treatment of tumour H09. (A) Plots showing the copy number ratio before vs after treatment of the indicated genes within amplified regions ( $\mathrm{H09}$, blue dot; other tumours, black dots). The copy number of ESR1, ATG5 and MSH2 increases after treatment, whereas that of PPM1D, PAK1 and NCOA3 is unchanged. The grey horizontal lines show the 0.999th quantiles of the ratios. (B) Genomic profiles showing the genes in A marked with arrows. (C and D) FISH for ESR1 before treatment (C) and after treatment (D). The red probe detects the centromere of chromosome 6, the green probe detects the ESR1 gene.

lives. In our study, more tumours had a pathological response over $50 \%$ in the anastrozole arm $(43 \%)$ than in the fulvestrant arm (25\%) but the size of the study and the slight imbalance between the arms in tumour size, node status and grade at enrolment mean differences of this size could easily arise by chance. Moreover, the Sataloff grading system was not originally designed to assess pathological response to neoadjuvant endocrine therapy and may not be a good surrogate marker for long-term survival (Dowsett et al, 2006; Chia et al, 2010). In contrast, changes in Ki67 expression have been widely studied to evaluate the response to neoadjuvant endocrine therapy (Dowsett et al, 2005; Dowsett et al, 2007; Dowsett et al, 2009; De Censi et al, 2011; Jonat and Arnold, 2011). Most tumours in both arms of our study showed a fall in Ki67 after therapy (Figure 2), and the magnitude of the changes was similar to that associated with favourable outcomes in previous studies. The similarity of the PEPI scores in the two arms likewise suggests that patients in the two treatment arms may have similar long-term outcomes (Dowsett et al, 2005; Ellis et al, 2008). However, this requires confirmation, especially in the light of recent data from the FIRST trial, indicating a PFS and OS advantage for fulvestrant in the metastatic setting (Robertson et al, 2014). Currently, the risk of relapse based on Ki-67 expression or the PEPI score strongly influences the decision whether to start adjuvant chemotherapy, but they will become less important if the ASTER study provides clear-cut evidence that patients over 70 years with high-grade tumours benefit from the addition of chemotherapy to hormonal therapy.

The most intriguing result from the genomic study was the simplification of copy number profiles after treatment. It is possible that these changes were simply a consequence of sampling from different sites within a clonally heterogeneous tumour. To rule this out would require high-depth analysis of samples taken from multiple sites within the surgical specimen. The alternative, and much more interesting, possibility is that the differences reflect clonal selection by the treatment. As it is not possible for a tumour to correct large-scale rearrangements, the most plausible explanation under the clonal-selection hypothesis is that rearranged clones were eliminated by the treatment, leading to expansion of an ancestral clone with a related, but simpler, profile. Residual tumour after neoadjuvant hormonal therapy has previously been noted to show histological evidence of increased differentiation (Samarnthai et al, 2012). Transformation is accompanied by subtle changes in the spectrum of target genes regulated by ER $\alpha$, leading to a shift from transcription of tumour-suppressive, differentiation-linked genes towards the expression of oncogenic genes (Ross-Innes et al, 2012). A possible interpretation of our results is that cells cope with a reduction in ER-dependent survival signals by reducing the transcriptional stress associated with chromosomal imbalances. Clones emerging from such a selection would be more normal: better able to enter $G_{0}$, better able to differentiate and more responsive to oestrogen. This builds on so-called intrinsic tumour suppression', a concept that has been extensively characterised in model systems, in particular in studies on the MYC oncogene (Lowe et al, 2004). This model is also compatible with the increase in copy number of ESR1 in H09, which could be viewed as an adaptive response to offset the reduced availability of oestrogen in anastrozole-treated cells. That said, the clinical data point rather to a tumour that is indifferent to oestrogen: there was no change in tumour size, grade or Ki-67, and PR started at zero and stayed there. The numbers are too small to meaningfully correlate the genomic changes we observed with response to therapy, but they provide no immediate support for the idea that genomic simplification of heterogeneous tumours is a major resistance mechanism. In contrast with the variability of chromosomal arm copy numbers, the classic amplicons known to harbour driver oncogenes in breast cancer were almost invariably present both before and after treatment, consistent with the widely accepted view that breast tumours are addicted to the oncogenes on these 

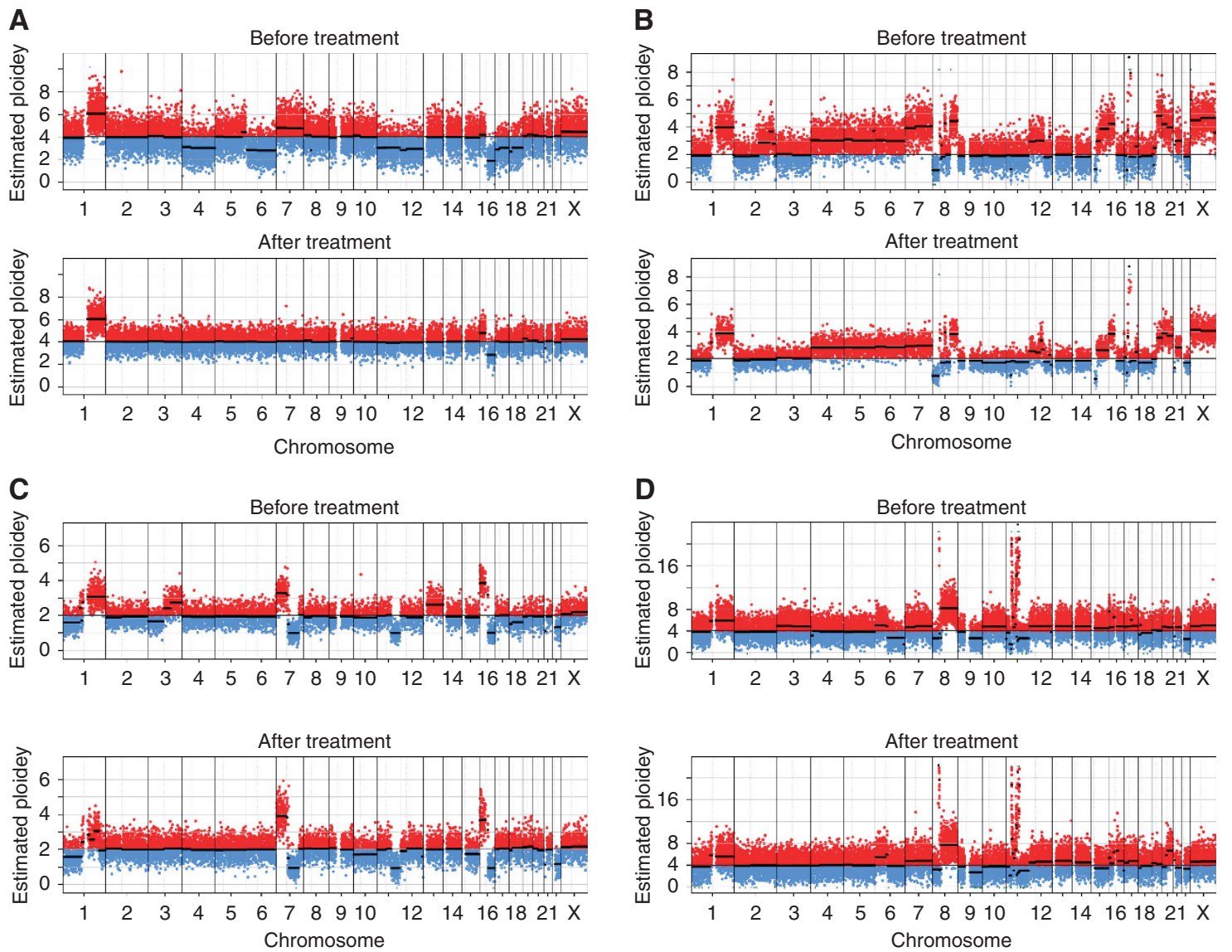

Figure 5. Genomic copy number profiles before and after treatment. (A) Tumour H13. (B) Tumour H08. (C) Tumour H10. (D) Tumour H19. Gains and losses of whole chromosomes or chromosome arms are seen after treatment. In many cases, these changes produce a less abnormal profile (see text for details).

amplicons. Amplification of ESR1 has a chequered history (Holst et al, 2007). Given the importance of oestrogen in the biology of breast cancer cells, ESR1 is an obvious candidate for amplification, but decades of research point instead to lineage choice as the main factor leading to $\mathrm{ER} \alpha$ expression in breast cancer. Our FISH results indicate that the appearance of the ESR1 amplicon in the copy number profile after treatment reflects clonal variation rather than de novo amplification. This clonal variation could be due to clonal selection by the treatment or sampling from different regions within a heterogeneous tumour (a 'needle placement artefact'), but whatever the mechanism, we can exclude ESR1 amplification as the initiating oncogenic event responsible for the $\mathrm{ER} \alpha$ positivity of this tumour.

In conclusion, the good response rates and low toxicity observed in this study show that both anastrozole and fulvestrant are effective and well-tolerated neoadjuvant hormonal treatments for post-menopausal women with large operable or locally advanced hormone-receptor-positive breast cancer. The results of the genomic study point to the re-emergence of tumour clones with less rearranged genomes as a potential new mechanism of resistance to endocrine therapy, but, given the potential for sampling effects, larger studies testing multiple biopsies from each tumour will be required to clarify whether this a reproducible, clinically important phenomenon.

\section{ACKNOWLEDGEMENTS}

We thank Jone Iriondo and Pippa McKelvie-Sebileau of the Institut Bergonié for editorial assistance. This work was supported by
INCA (plbio 2010-216 and INCa-DGOS-Inserm 6046); La Ligue Contre le Cancer (Equipe Labellisee 2011); Yorkshire Cancer Research Campaign (L341PA); La Fondation Widmer Contre le Cancer; AstraZeneca contributed to this study with an Educational Grant to Institut Bergonié and by providing Anastrozole (ARIMIDEX) and fulvestrant (FASLODEX). The funding sources had no role in the design of the study; the collection, analysis or interpretation of the data; or in the writing of the manuscript The study complies with current French laws.

\section{CONFLICT OF INTEREST}

The authors declare no conflict of interest.

\section{REFERENCES}

Ali S, Coombes RC (2002) Endocrine-responsive breast cancer and strategies for combating resistance. Nat Rev Cancer 2(2): 101-112.

Carpenter R, Doughty JC, Cordiner C, Moss N, Gandhi A, Wilson C, Andrews C, Ellis G, Gui G, Skene AI (2014) Optimum duration of neoadjuvant letrozole to permit breast conserving surgery. Breast Cancer Res Treat 144(3): 569-576.

Chia YH, Ellis MJ, Ma CX (2010) Neoadjuvant endocrine therapy in primary breast cancer: indications and use as a research tool. Br J Cancer 103(6): 759-764.

Ciruelos E, Pascual T, Arroyo Vozmediano ML, Blanco M, Manso L, Parrilla L, Munoz C, Vega E, Calderon MJ, Sancho B, Cortes-Funes H (2014) The therapeutic role of fulvestrant in the management of patients with hormone receptor-positive breast cancer. Breast 23(3): 201-208. 
De Censi A, Guerrieri-Gonzaga A, Gandini S, Serrano D, Cazzaniga M, Mora S, Johansson H, Lien EA, Pruneri G, Viale G, Bonanni B (2011) Prognostic significance of Ki-67 labeling index after short-term presurgical tamoxifen in women with ER-positive breast cancer. Ann Oncol 22(3): 582-587.

Debled M, Auxepaules G, de Lara CT, Garbay D, Brouste V, Bussieres E, Mauriac L, MacGrogan G (2014) Neoadjuvant endocrine treatment in breast cancer: analysis of daily practice in large cancer center to facilitate decision making. Am J Surg 208(5): 756-763.

Dixon JM, Renshaw L, Macaskill EJ, Young O, Murray J, Cameron D, Kerr GR, Evans DB, Miller WR (2009) Increase in response rate by prolonged treatment with neoadjuvant letrozole. Breast Cancer Res Treat 113(1): 145-151.

Dowsett M, A'Hern R, Salter J, Zabaglo L, Smith IE (2009) Who would have thought a single Ki67 measurement would predict long-term outcome? Breast Cancer Res 11(Suppl 3): S15.

Dowsett M, Nielsen TO, A'Hern R, Bartlett J, Coombes RC, Cuzick J, Ellis M, Henry NL, Hugh JC, Lively T, McShane L, Paik S, Penault-Llorca F, Prudkin L, Regan M, Salter J, Sotiriou C, Smith IE, Viale G, Zujewski JA, Hayes DF. International Ki-67 in Breast Cancer Working G (2011) Assessment of Ki67 in breast cancer: recommendations from the International Ki67 in Breast Cancer working group. J Natl Cancer Inst 103(22): 1656-1664.

Dowsett M, Smith IE, Ebbs SR, Dixon JM, Skene A, A'Hern R, Salter J, Detre S, Hills M, Walsh G (2007) Prognostic value of Ki67 expression after short-term presurgical endocrine therapy for primary breast cancer. J Natl Cancer Inst 99(2): 167-170.

Dowsett M, Smith IE, Ebbs SR, Dixon JM, Skene A, Griffith C, Boeddinghaus I, Salter J, Detre S, Hills M, Ashley S, Francis S, Walsh G (2005) Shortterm changes in Ki-67 during neoadjuvant treatment of primary breast cancer with anastrozole or tamoxifen alone or combined correlate with recurrence-free survival. Clin Cancer Res 11(2 Pt 2): 951s-958s.

Dowsett M, Smith IE, Ebbs SR, Dixon JM, Skene A, Griffith C, Boeddinghaus I, Salter J, Detre S, Hills M, Ashley S, Francis S, Walsh G, A'Hern R (2006) Proliferation and apoptosis as markers of benefit in neoadjuvant endocrine therapy of breast cancer. Clin Cancer Res 12(3 Pt 2): 1024s-1030s.

Eiermann W, Paepke S, Appfelstaedt J, Llombart-Cussac A, Eremin J, Vinholes J, Mauriac L, Ellis M, Lassus M, Chaudri-Ross HA, Dugan M, Borgs M (2001) Preoperative treatment of postmenopausal breast cancer patients with letrozole: A randomized double-blind multicenter study. Ann Oncol 12(11): 1527-1532.

Ellis MJ, Suman VJ, Hoog J, Lin L, Snider J, Prat A, Parker JS, Luo J, DeSchryver K, Allred DC, Esserman LJ, Unzeitig GW, Margenthaler J, Babiera GV, Marcom PK, Guenther JM, Watson MA, Leitch M, Hunt K, Olson JA (2011) Randomized phase II neoadjuvant comparison between letrozole, anastrozole, and exemestane for postmenopausal women with estrogen receptor-rich stage 2 to 3 breast cancer: clinical and biomarker outcomes and predictive value of the baseline PAM50-based intrinsic subtype-ACOSOG Z1031. J Clin Oncol 29(17): 2342-2349.

Ellis MJ, Tao Y, Luo J, A'Hern R, Evans DB, Bhatnagar AS, Chaudri Ross HA, von KA, Miller WR, Smith I, Eiermann W, Dowsett M (2008) Outcome prediction for estrogen receptor-positive breast cancer based on postneoadjuvant endocrine therapy tumor characteristics. J Natl Cancer Inst 100(19): 1380-1388.

Gusnanto A, Wood HM, Pawitan Y, Rabbitts P, Berri S (2012) Correcting for cancer genome size and tumour cell content enables better estimation of copy number alterations from next-generation sequence data. Bioinformatics 28(1): 40-47.

Holst F, Stahl PR, Ruiz C, Hellwinkel O, Jehan Z, Wendland M, Lebeau A, Terracciano L, Al-Kuraya K, Janicke F, Sauter G, Simon R (2007) Estrogen receptor alpha (ESR1) gene amplification is frequent in breast cancer. Nat Genet 39(5): 655-660.

Hostein I, Stock N, Soubeyran I, Marty M, De Mascarel I, Bui M, Geneste G, Petersen MC, Coindre JM, Macgrogan G (2011) Nucleic acid quality preservation by an alcohol-based fixative: comparison with frozen tumors in a routine pathology setting. Diagn Mol Pathol 20(1): 52-62.

Howell A, Robertson JF, Abram P, Lichinitser MR, Elledge R, Bajetta E, Watanabe T, Morris C, Webster A, Dimery I, Osborne CK (2004) Comparison of fulvestrant versus tamoxifen for the treatment of advanced breast cancer in postmenopausal women previously untreated with endocrine therapy: a multinational, double-blind, randomized trial. J Clin Oncol 22(9): 1605-1613.
Jonat W, Arnold N (2011) Is the Ki-67 labelling index ready for clinical use? Ann Oncol 22(3): 500-502.

Kalyuga M, Gallego-Ortega D, Lee HJ, Roden DL, Cowley MJ, Caldon CE, Stone A, Allerdice SL, Valdes-Mora F, Launchbury R, Statham AL, Armstrong N, Alles MC, Young A, Egger A, Au W, Piggin CL, Evans CJ, Ledger A, Brummer T, Oakes SR, Kaplan W, Gee JM, Nicholson RI, Sutherland RL, Swarbrick A, Naylor MJ, Clark SJ, Carroll JS, Ormandy CJ (2012) ELF5 suppresses estrogen sensitivity and underpins the acquisition of antiestrogen resistance in luminal breast cancer. PLoS Biol 10(12): e1001461.

Kuter I, Gee JM, Hegg R, Singer CF, Badwe RA, Lowe ES, Emeribe UA, Anderson E, Sapunar F, Finlay P, Nicholson RI, Bines J, Harbeck N (2012) Dose-dependent change in biomarkers during neoadjuvant endocrine therapy with fulvestrant: results from NEWEST, a randomized Phase II study. Breast Cancer Res Treat 133(1): 237-246.

Lowe SW, Cepero E, Evan G (2004) Intrinsic tumour suppression. Nature 432(7015): 307-315.

Massarweh S, Tham YL, Huang J, Sexton K, Weiss H, Tsimelzon A, Beyer A, Rimawi M, Cai WY, Hilsenbeck S, Fuqua S, Elledge R (2011) A phase II neoadjuvant trial of anastrozole, fulvestrant, and gefitinib in patients with newly diagnosed estrogen receptor positive breast cancer. Breast Cancer Res Treat 129(3): 819-827.

Mathew J, Asgeirsson KS, Jackson LR, Cheung KL, Robertson JF (2009) Neoadjuvant endocrine treatment in primary breast cancer-review of literature. Breast 18(6): 339-344.

Mauriac L, Debled M, Durand M, Floquet A, Boulanger V, Dagada C, Trufflandier N, MacGrogan G (2002) Neoadjuvant tamoxifen for hormone-sensitive non-metastatic breast carcinomas in early postmenopausal women. Ann Oncol 13(2): 293-298.

Mauriac L, Pippen JE, Quaresma AJ, Gertler SZ, Osborne CK (2003) Fulvestrant (Faslodex) versus anastrozole for the second-line treatment of advanced breast cancer in subgroups of postmenopausal women with visceral and non-visceral metastases: combined results from two multicentre trials. Eur J Cancer 39(9): 1228-1233.

Piva M, Domenici G, Iriondo O, Rabano M, Simoes BM, Comaills V, Barredo I, Lopez-Ruiz JA, Zabalza I, Kypta R, Vivanco M (2014) Sox2 promotes tamoxifen resistance in breast cancer cells. EMBO Mol Med 6(1): 66-79.

R Core Team (2013) R: A Language and Environment for Statistical Computing. R Foundation for Statistical Computing: Vienna, Austria.

Robertson JF, Lindemann JP, Llombart-Cussac A, Rolski J, Feltl D, Dewar J, Emerson L, Dean A, Ellis MJ (2012) Fulvestrant $500 \mathrm{mg}$ versus anastrozole $1 \mathrm{mg}$ for the first-line treatment of advanced breast cancer: follow-up analysis from the randomized 'FIRST' study. Breast Cancer Res Treat 136(2): 503-511.

Robertson JF, Llombart-Cussac A, Feltl D, Dewar J, Jasiowka M, Hewson N, Rukazenkov Y, Ellis MJ (2014) Fulvestrant $500 \mathrm{mg}$ versus anastrozole as first-line treatment for advanced breast cancer: overall survival from the phase II 'FIRST' study. SABCS S6-04.

Ross-Innes CS, Stark R, Teschendorff AE, Holmes KA, Ali HR, Dunning MJ, Brown GD, Gojis O, Ellis IO, Green AR, Ali S, Chin SF, Palmieri C, Caldas C, Carroll JS (2012) Differential oestrogen receptor binding is associated with clinical outcome in breast cancer. Nature 481(7381): 389-393.

Samarnthai N, Elledge R, Prihoda TJ, Huang J, Massarweh S, Yeh IT (2012) Pathologic changes in breast cancer after anti-estrogen therapy. Breast $J$ 18(4): 362-366.

Sataloff DM, Mason BA, Prestipino AJ, Seinige UL, Lieber CP, Baloch Z (1995) Pathologic response to induction chemotherapy in locally advanced carcinoma of the breast: a determinant of outcome. J Am Coll Surg 180(3): 297-306.

Segal CV, Dowsett M (2014) Estrogen receptor mutations in breast cancernew focus on an old target. Clin Cancer Res 20(7): 1724-1726.

Semiglazov VF, Semiglazov VV, Dashyan GA, Ziltsova EK, Ivanov VG, Bozhok AA, Melnikova OA, Paltuev RM, Kletzel A, Berstein LM (2007) Phase 2 randomized trial of primary endocrine therapy versus chemotherapy in postmenopausal patients with estrogen receptor-positive breast cancer. Cancer 110(2): 244-254.

Smith IE, Dowsett M, Ebbs SR, Dixon JM, Skene A, Blohmer JU, Ashley SE, Francis S, Boeddinghaus I, Walsh G (2005) Neoadjuvant treatment of postmenopausal breast cancer with anastrozole, tamoxifen, or both in combination: the Immediate Preoperative Anastrozole, Tamoxifen, or Combined with Tamoxifen (IMPACT) multicenter double-blind randomized trial. J Clin Oncol 23(22): 5108-5116. 
Weis KE, Ekena K, Thomas JA, Lazennec G, Katzenellenbogen BS (1996) Constitutively active human estrogen receptors containing amino acid substitutions for tyrosine 537 in the receptor protein. Mol Endocrinol 10(11): 1388-1398.

Wood HM, Belvedere O, Conway C, Daly C, Chalkley R, Bickerdike M, McKinley C, Egan P, Ross L, Hayward B, Morgan J, Davidson L, MacLennan K, Ong TK, Papagiannopoulos K, Cook I, Adams DJ, Taylor GR, Rabbitts P (2010) Using next-generation sequencing for high resolution multiplex analysis of copy number variation from nanogram quantities of DNA from formalin-fixed paraffin-embedded specimens. Nucleic Acids Res 38(14): e151.

(c) (1) (2) (2) This work is licensed under the Creative Commons Attribution-Non-Commercial-Share Alike 4.0 International License. To view a copy of this license, visit http:// creativecommons.org/licenses/by-nc-sa/4.0/

Supplementary Information accompanies this paper on British Journal of Cancer website (http://www.nature.com/bjc) 